\title{
A 2-Year Demographic Study of Domestic Paediatric Hand Injuries Requiring Surgical Intervention in An Urban Hospital
}

\author{
A Shalimar, MS (Ortho), S Jamari, MS (Ortho), AR Abdul Halim, MS (Ortho), \\ SA Roohi, MS (Ortho), AS Naicker, (MMed Rehab), I Sharaf, MS (Ortho) \\ Hospital Universiti Kebangsaan Malaysia (HUKM), Kuala Lumpur, Malaysia
}

\begin{abstract}
Domestic paediatric hand injuries make up the bulk of overall paediatric hand injuries. This is a retrospective study of domestic paediatric hand injuries admitted into an urban hospital that required surgical intervention. The most common injuries sustained were tendon injuries (24\%), total amputations (20\%) and laceration wounds (16\%). Accordingly the most common surgical interventions were tendon repairs (28\%), toilet suturing (24\%) and refashioning $(20 \%)$. Parents and care providers need to be more vigilant and careful when supervising children including ensuring the safe storage of dangerous items. Sharp items may require additional safety features and warning labels.
\end{abstract}

Key Words:

Paediatric hand injuries, Domestic, Surgical intervention

\section{INTRODUCTION}

Hand injuries are common in children because the hand is the part of the body which the child utilises to explore and satisfy their inquisitive and curious nature. Unfortunately, these injuries can be serious and may be associated with severe morbidity or permanent disability. Neglect ${ }^{1}$ and accidental trauma continue to be the main reasons cited for children's hand injuries. However, it is encouraging to note that most children with hand injuries will have a good outcome as inherently they have rapid healing ability². Still, appropriate treatment and follow-up is important to ensure optimum outcome of the injury.

Bhende $^{3}$ studied 477 paediatric hand injuries of which $60.8 \%$ occurred in domestic setting. A similar study conducted in Zimbabwe reported that 2 out of 3 hand injuries in children were a result of domestic accidents ${ }^{4}$. A large Danish study of 50,272 injuries in both adults and children revealed that $28.6 \%$ of all injuries involved the hand and wrist ${ }^{5}$. Within this group, $34 \%$ were due to domestic accidents. Domestic accident is one of the main causes of hand injuries. ${ }^{6}$ The aim of this study was to describe the causes of hand injuries in Malaysian population and investigate any potential relationship between occurrence of such accidents and time of day; site, nature, severity of injury; type of intervention necessary; and the quality of outcome.

\section{MATERIALS AND METHODS}

Paediatric patients (age 16y or less) who presented between the 1st of March 2003 and the 28th of February 2005 at our institution were included into this study. The study proposal was approved by the ethical committee of our institution. Information about the injury were divided into 4 major categories.

(I) Place where injury occurred

We classify the causes into 5 groups for comparison. (a) domestic (occurring in the home or associated with household chores), (b) traffic (caused by motor vehicle accidents), (c) school (occurring in the school), (d) leisure (associated with sports or recreational activities outside the house and school) and (e) other causes (injuries not classified under the above categories)

\section{(II)Time of injury}

Basically between working and non working hours of the day.

\section{(III) Site of hand injury}

The injury may accur at the radial, central or ulnar aspect of the hand. Each region can be further divided into distal, central or proximal zones. Based on the diagram in table I, sites I, II and III are located distally, Sites IV, V and VI are located centrally and Sites VII, VIII and XI are located proximally.

\section{(IV) Cause of injury}

We divided the injuries into mechanical and non mechanical causes. Those 2 categories are further subdivided into those caused by blunt and sharp objects. 
Table I: Site of Injury (Based on the "Tic-Tac-Toe" classification")

\begin{tabular}{|lccc|}
\hline $\begin{array}{l}\text { Site of Injury } \\
\text { ZONE }\end{array}$ & RADIAL & CENTRAL & ULNAR \\
\hline DISTAL & I & II & III \\
CENTRAL & Thumb P1, P2 & Index, Middle P1, P2, P3 & Ring, Small P1,P2,P3 \\
& IV & VI & Ring, Small MC \\
PROXIMAL & Thumb MC & Index, Middle MC & IX \\
& Scaphoid, Trapezium, Trapezoid & Capitate Lunate & Hamate, Triquetrum, Pisiform \\
\hline
\end{tabular}

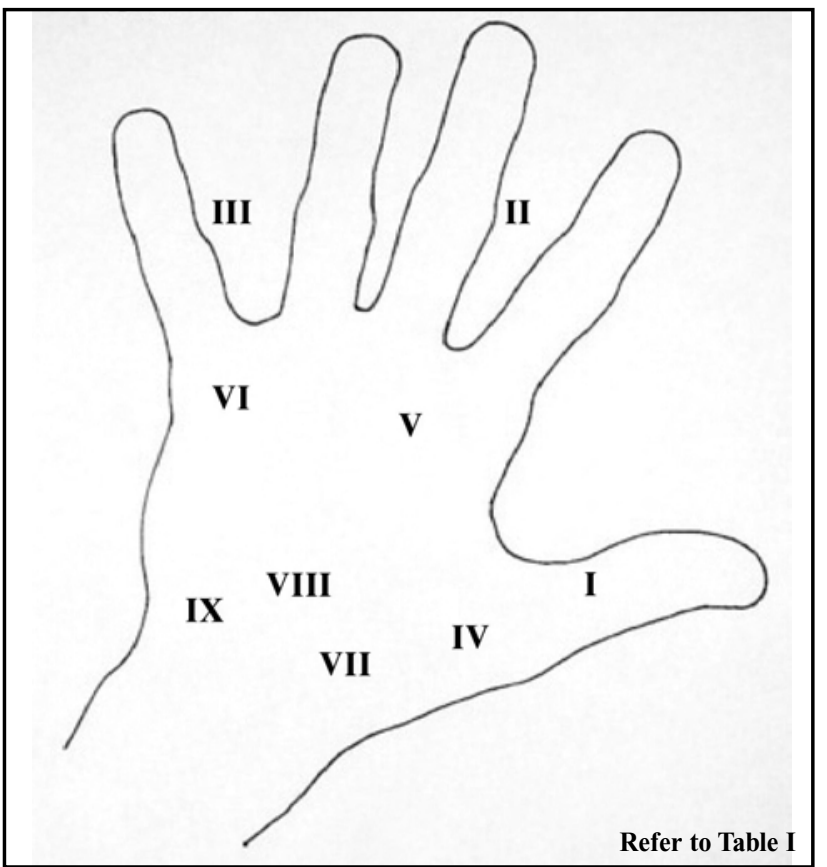

Information regarding severity of injury was documented (in ascending severity): superficial laceration wound, fingertip injury, tendon injury, nerve and artery injury, bony fracture, partial amputation, total amputation and crush injury. Surgical intervention was categorized into the following types (in ascending difficulty): wound toilet and suturing; skin graft; nail bed repair; tendon repair; nerve repair; revascularisation; bony fixation; replantation and refashioning. Only the most severe injury sustained and the most difficult surgery performed will be considered for analysis.

In a smaller group of patients with complete follow up information, we evaluated the functional outcome of treatment based on their competency in carrying out activities of daily living (ADL). This method was designed with the help of the occupational therapy unit of our institution.

\section{RESULTS}

Folders of 52 paediatric hand injury cases requiring surgical intervention were retrieved from the medical records office. Domestic injuries contributed $48 \%$ of the cases, traffic accidents accounted for $19 \%$ while injuries during school activities and leisure activities at 15\% and 12\% respectively. (Fig. 1).

Seventy-two per cent of the injured children were male and $28 \%$ were female. The racial breakdown was as follows: $72 \%$ Malays; $10 \%$ Chinese; and $8 \%$ Indians. The children were categorised in the following three educational levels: preschool $(8 \%)$; primary school $(32 \%)$; and secondary school $(60 \%)$.

Seventy-two per cent of the injuries occurred during working hours whilst $28 \%$ occurred during non-working hours. None of the domestic injuries were caused by thermal, chemical or biological causes. Forty-four per cent of the injuries were due to electrical appliances, out of which $16 \%$ were sharp (e.g., blender) and $28 \%$ were blunt (e.g., sugarcane machine). Fifty-six per cent of the cases were due to non electrical items, out of which $32 \%$ were sharp (e.g., knives, scissors) and $24 \%$ were blunt (e.g., door gaps) (Fig. 2).

Not surprisingly, most injuries occur at the distal zones of the hand. There were 14 cases at Site II, 7 cases each at Site I and III. Site V had 4 cases, site VI and IX had 2 cases and the rest (Site IV, VII and VIII) had only 1 case each. We note that $92 \%$ of the cases seen were children with right hand dominance.

Most of the cases (44\%), occurred at the end of the year (from October to December) coinciding with the long school holidays and festival season. Another peak was seen in the period of January to March with $28 \%$ of cases. April to June had $20 \%$ of cases whilst only $8 \%$ of cases occurred between July and September (Fig. 3).

Regarding the severity of hand injuries in this study sample, analysis demonstrated a broad spectrum of severity ranging from mild to severe. Twenty-four per cent of the cases involved tendon injuries, $20 \%$ of cases involved total amputation, $16 \%$ were superficial lacerations, $16 \%$ were fingertip injuries, $12 \%$ were crushed injuries whilst nerve and artery injuries, fractures and partial amputations each occurred in $4 \%$ of the cases studied (Fig. 4).

Of the cases studied, $28 \%$ required tendon repair, $24 \%$ toilet and suturing, $20 \%$ refashioning, $12 \%$ skin grafting and $4 \%$ for each of bony fixation, replantation, nail bed repair and nerve repair (Fig. 5). There were no cases of revascularisation. 


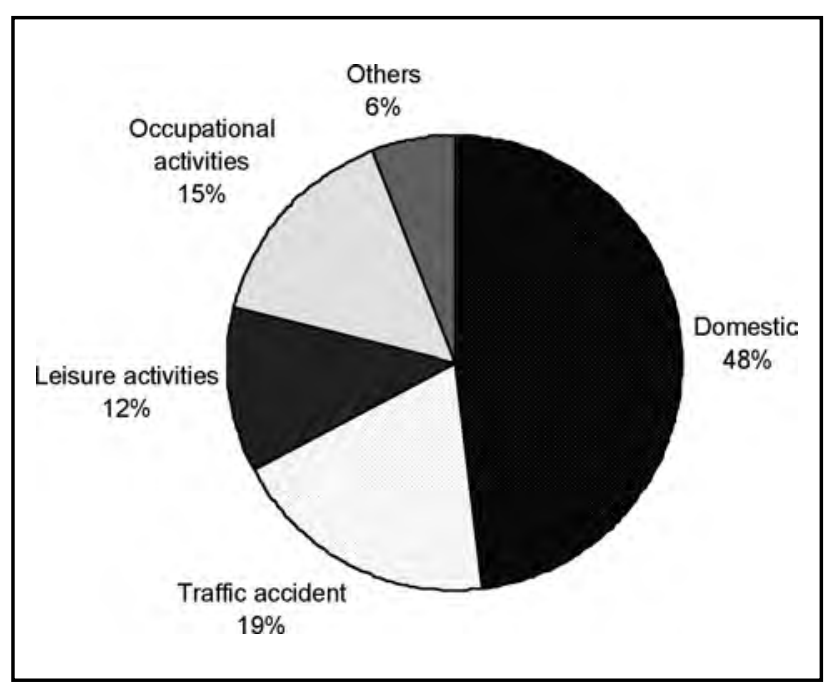

Fig. 1: Causes of Paediatric Hand Injuries.

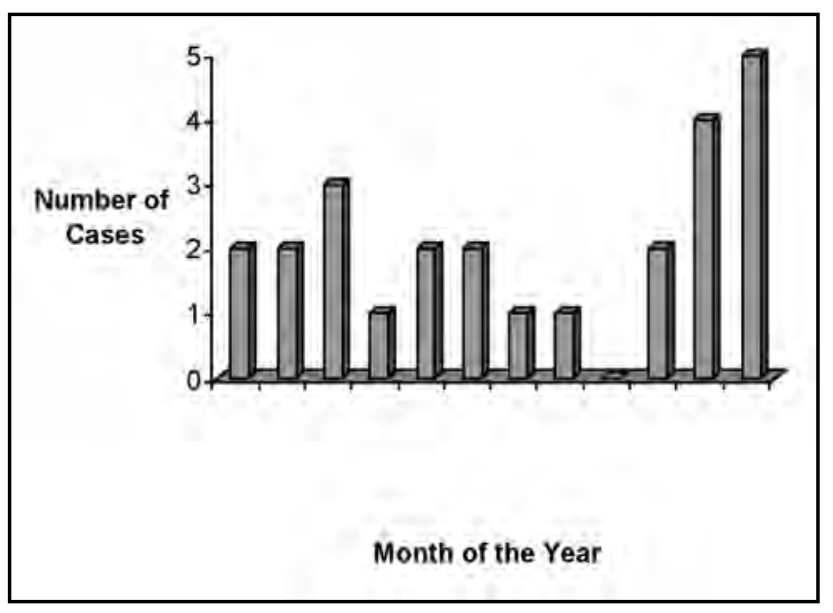

Fig. 3: Injuries rates for the different months in a year.

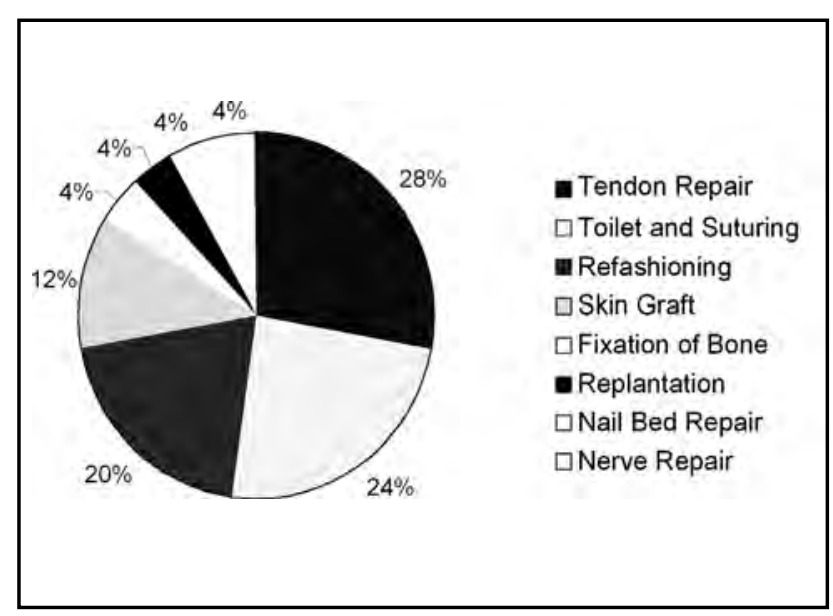

Fig. 5: Surgical Intervention in Domestic Paediatric Hand Injuries.

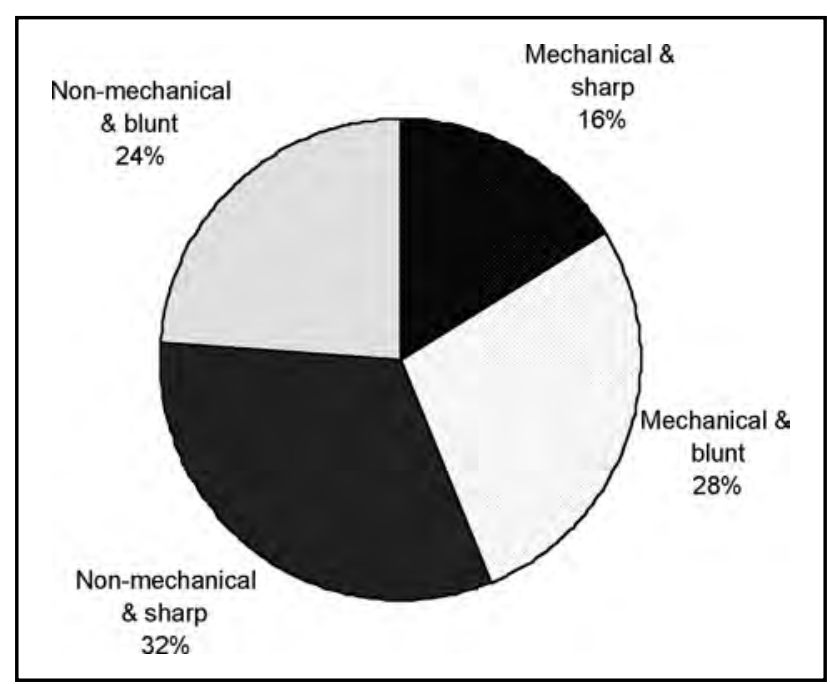

Fig. 2: Nature of Injury in Domestic Paediatric Hand Injuries.

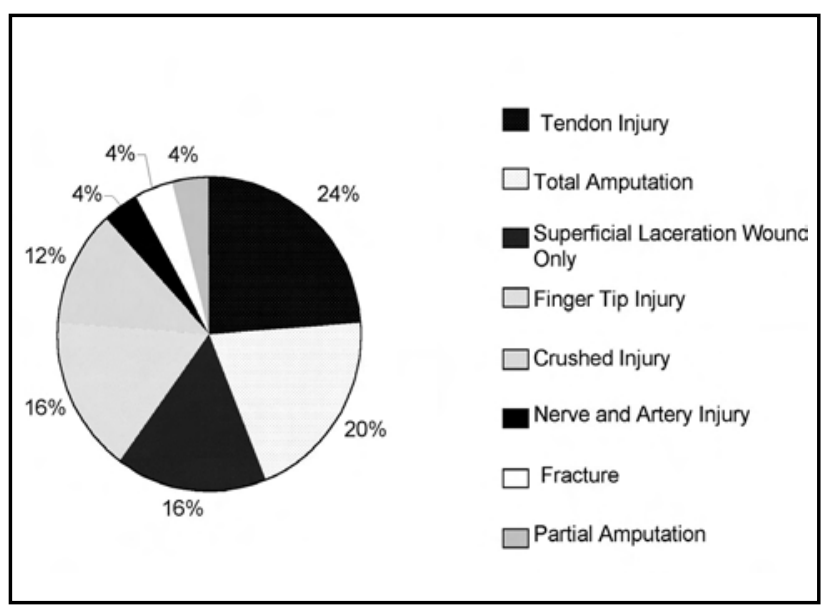

Fig. 4: Severity of Domestic Paediatric Hand Injuries.

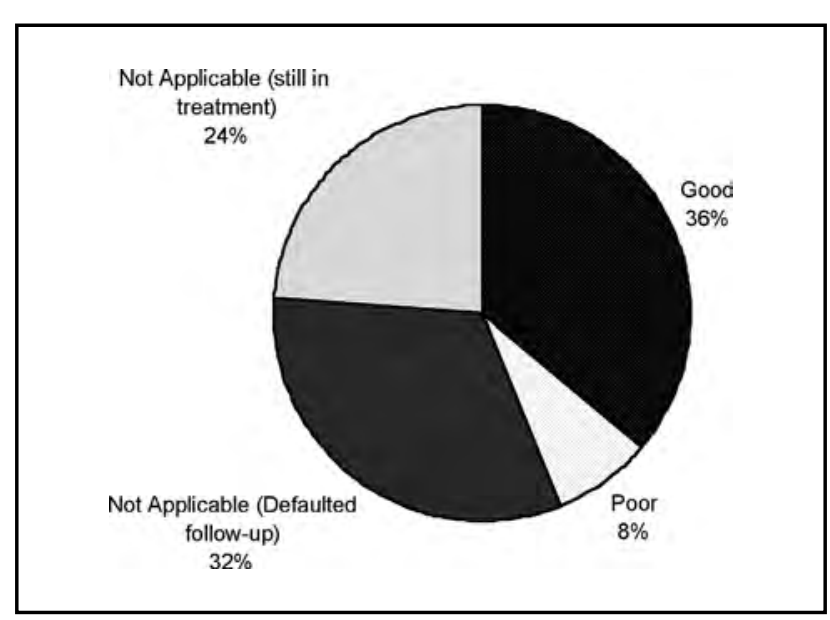

Fig. 6: Outcome of Domestic Paediatric Hand Injuries. 
In $44 \%$ of children outcome evaluation was performed. Good outcome was reported in $36 \%$ of the cases whilst only $8 \%$ had poor outcome. We were unable to evaluate most of the children (56\%) because $32 \%$ had defaulted follow-up while $24 \%$ were still undergoing treatment. (Fig 6). The general follow-up schedule is a minimum of 2 years after injury.

\section{DISCUSSION}

Paediatric hand injuries are challenging for both the hand surgeon and paediatrician. Bhende ${ }^{3}$ and $\mathrm{Al}-\mathrm{Hoqail}^{8}$ noted that domestic injuries form the main bulk of paediatric hand injuries. Similarly, we find that $48 \%$ of the injuries analyzed as part of this study were domestic injuries. As most children spend the majority of their time at home, it is not surprising that domestic hand injuries are the most common of those studied. Traffic accidents made up 19\%, occupational or school-related injuries $15 \%$ and leisure activity injuries at $12 \%$ of the accidents in this study.

Boys are more likely to sustain hand injury than girls, with a ratio of 2.6:1. This is an expected finding as boys tend to indulge in more rough and dangerous activities. Similar finding was reported by Bhende $^{3}$, Street ${ }^{6}$, Perks ${ }^{9}$ and Rasheed $^{10}$. The age group with the most hand injuries was between 13-16 years (secondary school attendees). Children in this age group are likely to be more independent and bold yet do not possess adequate knowledge, skill and dexterity to handle unfamiliar tools. It has been noted that different types of injuries tend to occur more frequently in certain age groups. For instance, lacerations and burns are more common in the younger age group whilst fractures, sprains and sports injuries are seen more in the older age group ${ }^{3,6}$. As expected more injuries occur during working hours than non-working hours. Since many parents are at work, children are perhaps not as well supervised as when parents are at home. This is also the time when children are at school or taking part in leisure activities, and are most active and inquisitive.

The most commonly injured area of the hand are the distal zones (i.e., sites I, II and III) which are the most exposed and vulnerable. These are also the most functional part of the hand especially in terms of sensation, handling and functional activities. Permanent disabilities may be very disabling.

Our study showed that most injuries were caused by non electrically powered items, because electrically powered items are less easily accessible at home. Injuries by sharp non electrical objects (e.g., knives, scissors) occurred most frequently at a rate of $32 \%$, followed by blunt electrical appliances (e.g., sugar cane machines, cake mixers) at $28 \%$. This is followed by blunt non electrical objects (e.g., doors) at $24 \%$ and finally sharp electrical appliances (e.g., blenders) at a rate of $16 \%$. Removing shoes and sitting on the floor is the cultural norm of this country, and it is common for domestic chores to be carried out on a mat on the floor. Since sharp items are sometimes placed on the floor, they contribute towards many of the injuries that occurred. One incident occurred during a festive celebration as the mother prepared cookies on the floor. She left a cake-mixer running and her daughter placed her finger into the running mixer. In general, injuries tend to occur more during the holidays and festive seasons as children spend more time playing at home and dangerous items such as firecrackers may be accessible.

In developed countries, sharp items are more likely to be stored in kitchen cabinets and holders (e.g., knife-holders). The items are also designed with safety features: scissors are more likely to have blunt tips and/or with safety shields. Most other studies were conducted in more developed nations where there is a higher usage of electrical items such as blenders, grinders and vacuum cleaners. Other causes commonly reported in the literature include lawn-mowers, escalators, washing machines, woodstove (burns), galvanized-iron fences, treadmills and spiked palisade railings $^{2,6,10-12}$. These items are less likely to be available here. Absence of non mechanical injuries in our study is probably due to selection bias since we only include injuries requiring surgical interventions. Al-Hoqail et al reported door gap injuries as the main cause of domestic injuries, but this is not a common occurrence here.

The most common injury found in this study was tendon injuries $(24 \%)$, followed by total amputation $(20 \%)$ and laceration wounds (16\%). Accordingly, the most common surgery performed was tendon repair followed by toilet and suturing and refashioning. Although we did not study the exact location of total amputations, there were most likely involved the distal part of finger tips resulting in refashioning as treatment. We classified each injury according to the structures involved (e.g., whether a tendon, artery, nerve or bone is involved), therefore it may difficult to make comparisons with other studies tht classify injuries differently. Bhende et $a l^{3}$ reported that the most common type of injury was laceration wounds at $38.1 \%$, followed by soft tissue injuries at $28.7 \%$ and fractures at $19.3 \%$. It is not clear which anatomical structures were involved.

Our study sample did not reflect the general racial composition of the country. Seventy-two per cent of the injuries analyzed in this study were in Malays, $10 \%$ Chinese and $8 \%$ Indian, whereas the makeup of our urban population is $60 \%$ Chinese, $30 \%$ Malay and $10 \%$ Indian. It is possible that many Chinese patients seek treatment at private hospitals as they are generally more financially well off than Indians and Malays, and are more likely to have medical insurance coverage. The Malays tend to have bigger families with up to 5 or 6 children and it may be more difficult for the parents to provide adequate supervision to prevent injuries. 
Most of these injuries were preventable and measures should be taken to reduce the incidence considering the potential loss of function of the involved upper limb.

\section{CONCLUSION}

Domestic paediatric hand injuries make up the bulk of overall paediatric hand injuries. Most of them occur during working hours, school holidays and involve the distal end of the hands. The most common injuries are tendon injuries, amputations and lacerations. Accordingly, the most common surgical interventions for paediatric hand injuries are tendon repairs, toilet suturings and refashioning of amputated stumps. The injuries span a wide spectrum of severity and surgical complexity of treatment, but the overall outcome has been good.

\section{ACKNOWLEDGEMENT}

We would like to thank the following medical students, Cheong Wai Seng, Lim Wei Chieh, Tang Yee Loong and Teo Pock Chin who assisted in the collection and analysis of data.

\section{REFERENCES}

1. Brown RL, Greenhalgh DG, Warden GD. Iron burns to the hand in the young paediatric patient: A problem in prevention. Curr Probs in Paeds. 1997; 27(10): 362-5.

2. Grob M, Josty IC, Soldin MG, Dickson WA. Paediatric friction hand injuries caused by domestic vacuum cleaners - a review from one unit. Burns. 2003; 29(7): 714-6.

3. Bhende S, Dandrea LA, Davis HW. Hand injuries in children presenting to a paediatric emergency department. Ann of Em Med. 1993; 22(10):1519-23.

4. Onuba O. Traumatic finger amputations in Bulawayo. Cent Afr Journal Med 1993; 39(3): 49-52.

5. Angermann P, Lohmann M. Injuries to the hand and wrist. A study of 50,272 injuries. J. Hand Surg. 1993; 18B:642-4.

6. Street JR, Wright JCE, Choo KL, Fraser JF, Kimble RM. Woodstoves uncovered: a paediatric problem. Burns. 2002; 28(5): 4724.

7. Weinzweig J, Weinzweig N. The "Tic-Tac-Toe" classification system for mutilating injuries of the hand. Plast Reconstr Surg. 1997; 100(5): 1200-11.

8. Al-Hoqail R, Al-Shlash SO. Hand injuries in children at King Fahd Hospital of the University of Saudi Arabia. African Journal Med Sci. 2000; 29(3-4): 289-91.

9. Perks AG, Penny M, Mutimer KL. Finger injuries to children involving exercises bicycles. Med J Aust. 1991; 155:368-70.

10. Rasheed T, Hill C, Khan K, Brennen M. Paediatric Hand Injuries caused by Spiked Railings. J. Hand Surg. 1999; 24B: 615-6.

11. Griffin PA, Robinson DN. Paediatric Hand Injuries and the galvanized iron-fence. Med J Austr. 1989; 150(11):6 44-5.

12. Abbas MI, Bamberger HB, Gebhart RW. Home Treadmill Injuries to Infants and Children aged 5 years: A Review of Consumer Product Safety Commission Data and an Illustrative Report of Case. J Amer Ortho Assoc. 2004; 104(9): 372-6. 